\title{
Измерение подвижности носителей заряда в арсениде галлия с помощью ближнеполевого сверхвысокочастотного микроскопа методом сверхвысокочастотного магнитосопротивления
}

\author{
(С) Д.А. Усанов, А.Э. Постельга, А.А. Калямин ", И.В. Шаров \\ Саратовский национальный исследовательский государственный университет им. Н.Г. Чернышевского, \\ 410012 Саратов, Россия \\ ฯ E-mail: alexey-gtp@mail.ru
}

(Получена 16 апреля 2018 г. Принята к печати 24 апреля 2018 г.)

Показана возможность бесконтактного неразрушающего локального измерения сверхвысокочастотной подвижности носителей заряда в арсениде галлия при помощи ближнеполевого сканирующего сверхвысокочастотного микроскопа с использованием эффекта сверхвысокочастотного магнитосопротивления. Отмечается необходимость учета при обработке результатов измерений влияния эффекта смещения сверхвысокочастотного поля.

DOI: 10.21883/FTP.2018.13.46867.8891

\section{1. Введение}

Измерение подвижности носителей заряда в полупроводниковых материалах и в структурах полупроводниковых приборов представляет интерес, так как знание этого параметра позволяет прогнозировать основные характеристики приборов на основе этих материалов [1]. Известные способы определения подвижности носителей заряда с использованием эффекта сверхвысокочастотного (СВЧ) магнитосопротивления [2-6] позволяли получать только усредненную по объему полупроводника подвижность носителей заряда. Их использование было также связано с ограничениями, накладываемыми на толщину исследуемого образца.

Благодаря высокой локальности и чувствительности ближнеполевой [7,8] СВЧ микроскопии открывается возможность регистрации изменения свойств полупроводниковых материалов при внешних воздействиях на образец, в частности изменения подвижности носителей заряда при воздействии на полупроводник внешнего магнитного поля. Способ, описанный в настоящей статье, использующий для измерения подвижности носителей заряда сканирующий ближнеполевой СВЧ микроскоп, позволяет измерять подвижность носителей заряда на сверхвысоких частотах бесконтактно с высокой степенью локальности, строить профили распределения подвижности носителей заряда вдоль координаты сканирования, измерять подвижность носителей заряда в полупроводниковых приборах при прохождении через них электрического тока, что выгодно отличает его от известных способов.

\section{2. Методика эксперимента}

Экспериментальные исследования проводились на установке, схема которой приведена на рис. 1, а. СВЧ излучение от генератора качающейся частоты направлялось через коаксиально-волноводный преобразователь в волновод, далее в низкоразмерный резонатор [9] измерительной головки 10 и через иглы-зонды на образец. Падающая волна 8 и отраженная волна 9 детектировались и попадали на вход панорамного измерителя коэффициента стоячей волны по напряжению (КСВН) и ослабления Я2Р-67 2. Результаты измерений оцифровывались с помощью аналого-цифрового преобразователя (АЦП) и поступали на компьютер 1 для обработки.

Исследуемый образец арсенида галлия, с концентрацией носителей заряда $1.5 \cdot 10^{17} \mathrm{~cm}^{-3}$, измеренной методом плазменного резонанса, и подвижностью $4100 \mathrm{~cm}^{2} /(\mathrm{B} \cdot \mathrm{c})$, определенной по номограммам для различных концентраций [10], имел геометрические размеры $12 \times 12 \times 1.25$ мм и закреплялся в непосредственной близости к сердечнику электромагнита таким образом, чтобы магнитное поле было параллельно его широкой грани (рис. 2). Учитывая малый размер зазора сердечника, магнитное поле можно считать квазиоднородным.

К широкой грани исследуемого образца подводился зонд ближнеполевого СВЧ микроскопа, в котором в качестве измерительной резонансной головки использовался низкоразмерный волноводный резонатор типа „индуктивная диафрагма-емкостная диафрагма“. При этом вектор напряженности электрического СВЧ поля между связанными с низкоразмерным резонатором близкорасположенными друг к другу на концах иглами-зондами был перпендикулярен вектору индукции магнитного поля. Расстояние между кончиками игл-зондов и образцом составляло 4 мкм (рис. 1,b).

Электромагнит калибровался с помощью линейного датчика Холла SS495A. Измерения модуля коэффициента отражения в полосе частот $(8.23-8.29$ ГГц) проводились с помощью измерителя КСВН и ослабления Я2Р-61 при различных значениях индукции магнитного поля, с последующей оцифровкой полученных результатов на персональной ЭВМ с помощью АЦП L-Card E14-140M. Индукция магнитного поля изменялась в пределах от -140 до 140 мТл. Полученная зависимость модуля ко- 

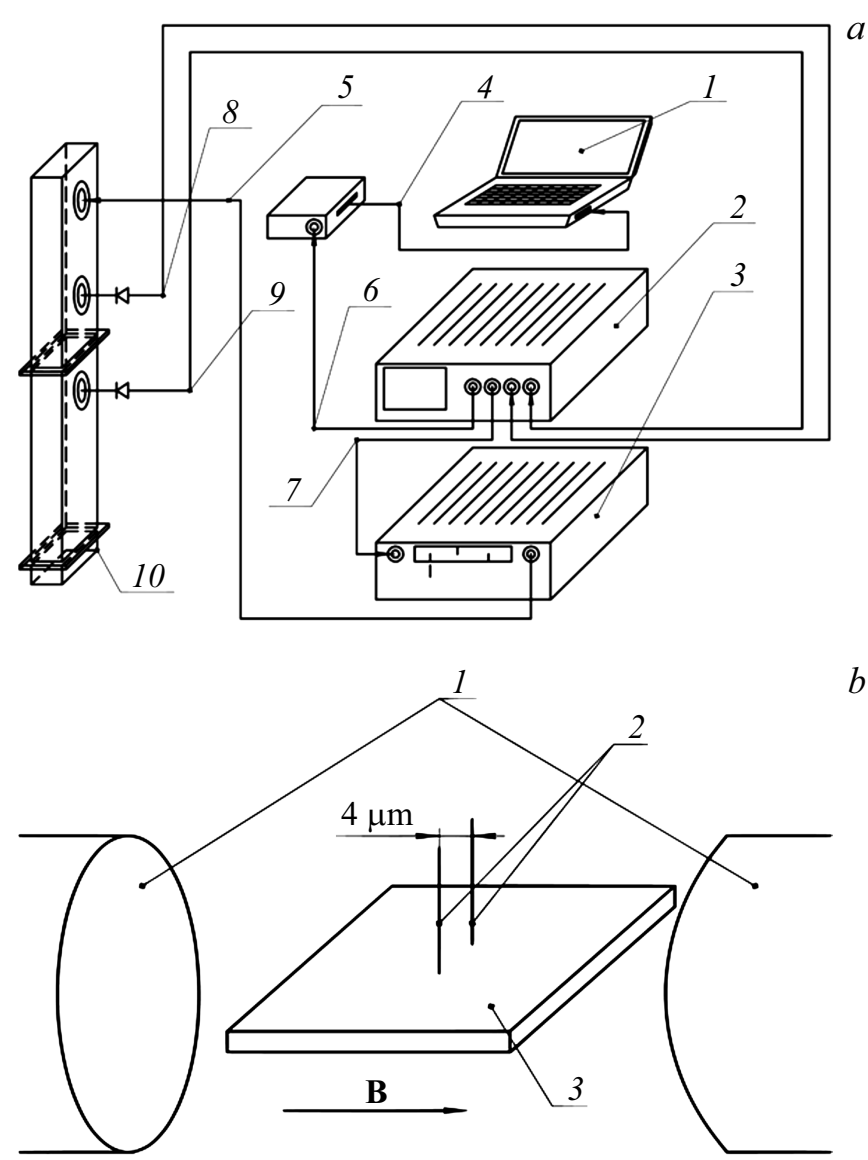

Рис. 1. $a-$ схематичное изображение измерительной установки: 1 - компьютер, 2 - панорамный измеритель КСВН и ослабления, 3 - генератор качающей частоты, 4 - цифровой сигнал, 5 - СВЧ сигнал, $6-$ аналоговый сигнал, $7-$ сигнал тактирования, 8 - падающая волна, $9-$ отраженная волна, 10 - измерительная головка. $b-$ схематичное взаиморасположение игл измерительного зонда, исследуемого образца и полюсов электромагнита: 1 - полюса электромагнита, 2 - иглы-зонды, 3 - исследуемый образец.

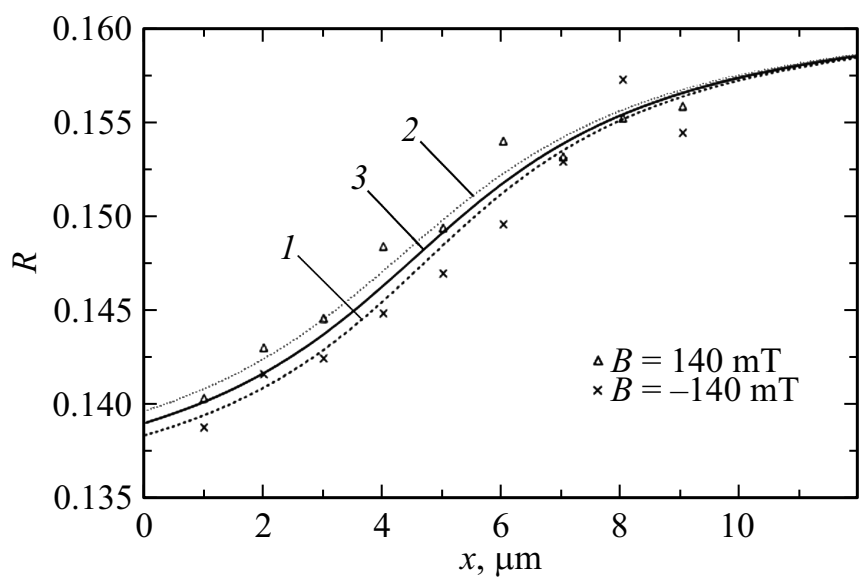

Рис. 2. Экспериментальная зависимость модуля коэффициента отражения $R$ от расстояния зонд-образец $x: 1-$ $B=-140$ мТл, $2-V=140$ мТл, $3-$ калибровочная кривая.

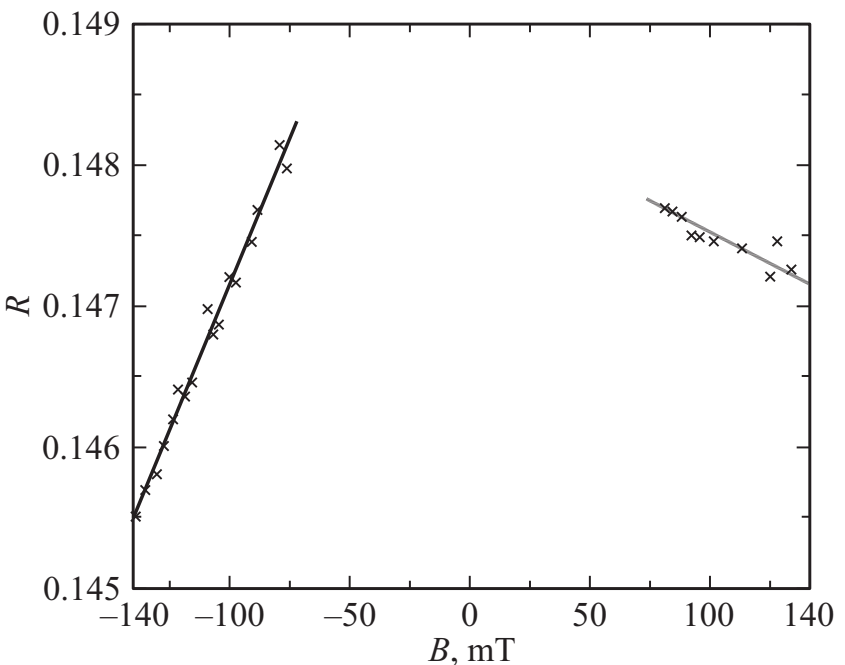

Рис. 3. Экспериментальная зависимость модуля коэффициента отражения $R$ от индукции магнитного поля $B$ : основное направление вектора индукции магнитного поля (пунктирная линия), противоположное направление вектора индукции магнитного поля (сплошная линия).

эффициента отражения от индукции магнитного поля представлена на рис. 3.

\section{3. Расчет подвижностей носителей заряда}

Для расчета искомой СВЧ подвижности носителей заряда в образце использовалось соотношение, применяемое в методах определения подвижности с использованием эффекта СВЧ магнитосопротивления [1-4]:

$$
\mu=\frac{1}{B} \sqrt{\frac{\alpha_{0}-\alpha}{\alpha}}
$$

где $\mu-$ СВЧ подвижность носителей заряда, $B-$ индукция магнитного поля, $\alpha_{0}$ - показатель поглощения в материале без магнитного поля, $\alpha-$ показатель поглощения в материале при индукции магнитного поля, равной $B$.

Для коэффициента прохождения по мощности $T$ использовалось соотношение [11]

$$
T=\frac{(1-R)^{2} \exp (-\alpha x)}{1-R^{2} \exp (-\alpha x)},
$$

где $x$ - глубина проникновения поля в полупроводнике, $R$ - коэффициент отражения по мощности, полученный в результате измерений.

Из закона Бугера-Ламберта и закона сохранения энергии имеем

$$
\exp (-\alpha x)=1-R-T \text {. }
$$

Решая систему уравнения (2) и (3) относительно $\alpha$, находим значения показателя поглощения для случаев 
нулевой индукции магнитного поля $\alpha_{0}$, а также $\alpha$ для значения индукции $B$.

Подставив полученные значения $\alpha_{0}, \alpha$ в выражение (1), вычисляем СВЧ подвижность носителей заряда.

Измеренный коэффициент отражения для противоположных направлений приложенного внешнего магнитного поля оказывается различен, что может быть объяснено эффектом смещения СВЧ поля либо по направлению к зондам, либо в противоположном направлении [12,13]. Такое смещение можно считать физически эквивалентным уменьшению или увеличению зазора между зондами и поверхностью полупроводника. Эффект смещения поля в рассматриваемом случае объясняется возникновением холловской составляющей СВЧ поля в зондах, которая, в зависимости от направления магнитного поля, либо суммируется, либо вычитается из наводимого в зондах поля. Эта дополнительная составляющая должна быть одинакова по величине для противоположных направлений магнитного поля и отличаться только знаком в случае линейной зависимости коэффициента отражения СВЧ излучения в области наблюдаемого резонанса от расстояния между концами зондов и измеряемой структурой. Экспериментальная зависимость модуля коэффициента отражения от расстояния между зондами и образцом представлена на рис. 2. Наблюдаемый на графике линейный участок зависимости $R$ от $x$ в области, соответствующей реальным значениям величины изменения зазора, связанным с эффектом смещения СВЧ поля, наблюдаемым в эксперименте по определению подвижности, позоволяет использовать формулу среднего арифметического (4) для устранения погрешности, возникающей из-за эффекта смещения поля:

$$
R=\frac{R_{+}+R_{-}}{2},
$$

где $R_{+}, R_{-}-$значения модуля коэффициента отражения для противоположных направлений внешнего магнитного поля.

Используя значение модуля коэффициента отражения, найденное с помощью выражения (4) для расстояния зонд-образец 4 мкм, на электронной вычислительной машине с помощью выражений (1)-(3) было получено значение подвижности носителей заряда $\mu=4190 \mathrm{~cm}^{2} /(\mathrm{B} \cdot \mathrm{c})$.

\section{4. Заключение}

Полученное значение СВЧ подвижности носителей заряда в арсениде галлия хорошо согласуется со справочными данными. Показанная в настоящей работе возможность измерения СВЧ подвижности носителей заряда с помощью сканирующего ближнеполевого СВЧ микроскопа и использования эффекта СВЧ магнитосопротивления открывает перспективу исследования с высокой степенью локальности сложных полупроводниковых структур, в том числе построения профилей распределения подвижности носителей заряда от координаты сканирования. Приведенная в настоящей статье методика измерений может найти применение для исследования и контроля полупроводниковых структур, приборов и микросхем в процессе их производства, а также в условиях прохождения через них тока.

\section{Список литературы}

[1] W. Chaisantikulwat, M. Mouis, G. Ghibaudo, C. Gallon, C. Fenouillet-Beranger, D.K. Maude, T. Skotnicki, S. Cristoloveanu. Solid-State Electron., 50 (4), 637 (2006).

[2] B. Molnar, T.A. Kenedy. J. Electrochem. Soc. Solid-State Sci. Technol., 125 (8), 1318 (1978).

[3] В.С. Банников, Ю.Г. Качуровский, И.В. Петренко. Электронная промышленность, 9, 48 (1982).

[4] С.М. Безручко, В.Н. Подшивалов, А.И. Фисун. Электронная промышленность, 3, 66 (1986).

[5] D. Usanov, A. Skripal, A. Abramov, A. Bogolubov, V. Skvortsov, M. Merdanov. Proc. 37rd Eur. Microwave Conf. (Munich, Germany, 2010) p. 198.

[6] D. Usanov, A. Skripal, D. Ponomarev, E. Latysheva, S. Nikitov. Proc. 20th Int. Conf. on Microwaves, Radar, and Wireless Communications MIKON-2014 (Gdansk, Poland, 2014) v. 1, p. 62.

[7] Д.А. Усанов. Ближнеполевая сканирующая СВЧ-микроскопия и области ее применения (Саратов, Изд-во Сарат. ун-та, 2010) c. 100.

[8] P. Gregory, J.F. Blackburn, K. Lees, R.N. Clarke, T.E. Hodgetts, S.M. Hanham, N. Klein. Ultramicroscopy, 161, 137 (2016)

[9] Д.А. Усанов, С.С. Горбатов. Приборы и техника эксперимента, 2, 100 (2006).

[10] M. Levinshtein, S. Rumyantsev, M. Shur. Handbook Series on Semiconductor Parameters (Singapore-New JerseyLondon-Hong Kong, World Scientific Publishing Co. Pte. Ltd, 1996) v. 1, p. 84.

[11] L.G. Parratt. Phys. Rev., 95, 359 (1954).

[12] H.E.M. Barlow, R. Koike. Proc. IEEE, 110 (12), 2177 (1963).

[13] Л.Н. Баранов, В.Б. Гаманюк, Д.А. Усанов. РЭ, 18 (11), 73 (1973).

Редактор Г.А. Оганесян

Measurement of charge carrier mobility in gallium arsenide by means of a near-field microwave microscope by the microwave magnetoresistance method

D.A. Usanov, A.E. Postelga, A.A. Kalyamin, I.V. Sharov

National Research Saratov State University named after N.G. Chernyshevsky, 410012 Saratov, Russia

Abstract The possibility of a non-contact, non-destructive local measurement of microwave carrier mobility in gallium arsenide is demonstrated using a near-field scanning microwave microscope using the effect of microwave magnetoresistance. It is noted that need to take into account the influence of the effect of microwave field displacement when processing the results of measurements. 